\title{
KOMPOSISI TIPE NEMATOSIT KARANG SCLERACTINIA, Pocillopora sp. DARI TERUMBU KARANG PANTAI TONTAYUO, BATUDAA PANTAI, GORONTALO
}

\author{
(Nematocysts Composition of Scleractinian Coral, Pocillopora sp. from the Reef at \\ Tontayuo Beach, Batudaa Pantai, Gorontalo)
}

\author{
Ajrin Y. Nusi ${ }^{1}$, Carolus P. Paruntu ${ }^{2}$, Antonius P. Rumengan ${ }^{2}$, Farnis B. Boneka ${ }^{2}$, Noldy \\ G.F. Mamangkey ${ }^{2}$, Laurentius Th.X. Lalamentik ${ }^{3}$
}

1. Mahasiswa Program Studi Ilmu Kelautan, FPIK, UNSRAT Manado

2. Staf Pengajar Program Studi IImu Kelautan, FPIK, UNSRAT Manado

3. Staf Pengajar Program Studi Budidaya Perairan, FPIK UNSRAT Manado

Penulis korespondensi: Carolus P. Paruntu; carolusparuntu@unsrat.ac.id

\begin{abstract}
The objective of this present study is to know the composition of nematocyst types from the coral Scleractinia, Pocillopora sp. The coral colonies of Pocillopora sp. were collected at Tontayuo coastal coral reefs, Batudaa Pantai, Gorontalo. This research was conducted for 3 months, from September-December 2020. The method of testing the type and composition of nematocysts was carried out using an Olympus CX41 type microscope with x100 objective lens magnification connected to a computer ST24 monitor equipped with optical view 7 application (software). Photos of Pocillopora sp. both alive and skeleton form are documented in this journal. The results of the current study showed that Pocillopora sp. has the types and composition of $\mathrm{MpM}$ of $91.49 \%$, while $\mathrm{HI}$ is $8.51 \%$. MpM is the dominant nematocyst in Pocillopora sp. Future research is recommended to identify this coral at the species level and to study more deeply the various coral species in the genus Pocillopora based on the types and morphology of nematocysts that are useful in the taxonomy of Scleractinia corals.
\end{abstract}

Keywords: Gorontalo, HI, MpM, nematocyst, Pocillopora sp., Scleractinian coral

\begin{abstract}
ABSTRAK
Penelitian sekarang ini bertujuan untuk mengetahui komposisi tipe-tipe nematosit pada karang keras (Scleractinia), Pocillopora sp. Koloni-koloni karang Pocillopora sp. dikumpulkan di terumbu karang pantai Tontayuo, Kecamatan Batudaa Pantai, Kabupaten Gorontalo, Provinsi Gorontalo. Penelitian ini dilakukan selama 3 bulan, dari September-Desember 2020. Metode pengujian tipe dan komposisi nematosit dilakukan dengan menggunakan mikroskop tipe Olympus CX41 dengan pembesaran lensa objektif x100 yang terhubung dengan Komputer ST24 monitor yang dilengkapi dengan aplikasi optica view 7 (software). Foto-foto dari Pocillopora sp. baik dalam keadaan hidup maupun dalam bentuk skeleton didokumentasikan dalam jurnal ini. Hasil penelitian sekarang ini memperlihatkan bahwa Pocillopora sp. memiliki tipe dan komposisi MpM sebesar 91,49\%, sedangkan $\mathrm{HI}$ 8,51\%. MpM merupakan nematosit yang dominan dalam Pocillopora sp. Penelitian ke depan disarankan untuk mengidentifikasi karang ini pada tingkatan spesies dan mempelajari lebih mendalam berbagai spesies karang dalam genus Pocillopora berdasarkan tipe dan morfologi nematosit yang berguna dalam taksonomi karang Scleractinia.
\end{abstract}

Kata kunci: Gorontalo, HI, MpM, nematosit, Pocillopora sp., karang Scleractinia 


\section{PENDAHULUAN}

Filum Cnidaria merupakan suatu kelompok fauna dimana dalam jaringan tubuh ektodermis-nya memiliki organ intraseluler yang unik. Cnidae digunakan oleh fauna Cnidaria untuk menyerang predator dan cnidaria lain di sekitarnya, menangkap mangsa, serta digunakan oleh larva karang untuk proses setelmen (Watson dan Wood, 1988; Fautin, 2009; Paruntu, dkk. 2020). Cnidae terdiri dari kapsul, tangkai, benang, dan cairan intrakapsular yang ada dalam sel cnidocyte (Mariscal, 1984; Paruntu, dkk. 2013; Paruntu, 2014; Paruntu dan Souw, 2014; Paruntu dan Darwisito, 2016). Cnidae terdiri dari tiga kelompok, yaitu ptikosit, spirosit, dan nematosit (Mariscal, 1984; Watson dan Wood, 1988). Nematosit berada dalam semua fauna dari filum Cnidaria, sedangkan ptikosit dan spirosit hanya berada pada sebagian fauna filum ini (Fautin, 2009).

Beberapa hasil penelitian nematosit karang di negara lain telah dilakukan oleh para ahli biologi karang, antara lain Hidaka dan Yamazato (1985) melaporkan bahwa perbedaan nyata morfologi nematosit ditemukan pada soft dan hard morph $G$. fascicularis dan juga pada $S$. mordax dan $S$. pistilata, dan dianggap jenis-jenis karang tersebut merupakan jenis berbeda. Perbedaan karakter nematosit sudah dipakai dalam taksonomi karang keras yang berasal dari ordo Scleractinia (Lang, 1986), dan juga taksonomi dalam ordo-ordo berbeda dari filum Cnidaria (Pires dan Pitombo, 1992). Perbedaan tipe dan morfologi nematosit pada setiap fase perkembangan karang keras, $P$. damicornis ditemukan mulai dari fase larva planula, koloni-koloni muda sampai pada koloni-koloni dewasa (Paruntu, dkk., 2000).

Penelitian tentang nematosit karang di Indonesia masih sangat jarang dilakukan, seperti yang diteliti oleh Paruntu, dkk. (2013) pada jenis karang Pocillopora eydouxi, $P$. verrucosa dan $P$. woodjonesi; Paruntu
(2014) pada $G$. fascicularis dengan perbedaan warna polip; Paruntu dan Souw (2014) pada Seriatopora hystrix, dan $S$. caliendrum; Paruntu dan Darwisito (2016) pada Pachyseris rugosa; dan Gagu dkk. (2019) pada Acropora divaricata dan $A$. florida.

Studi saat ini bertujuan untuk mengetahui tipe dan komposisi nematosit dari karang Scleractinia, Pocillopora sp.

\section{METODE PENELITIAN}

\section{Waktu dan Tempat}

Periode penelitian dari SeptemberDesember 2020. Sampel karang Pocillopora sp. (Lihat Gambar 2) diambil di perairan Tontayuo, Kecamatan Batudaa Pantai, Kabupaten Gorontalo, Provinsi Gorontalo (Gambar 1). Selanjutnya, sampel karang yang telah diambil diteliti di Laboratorium Biologi Laut dan Laboratorium Kesehatan Ikan, Lingkungan \& Toksikologi, FPIK UNSRAT, Manado.

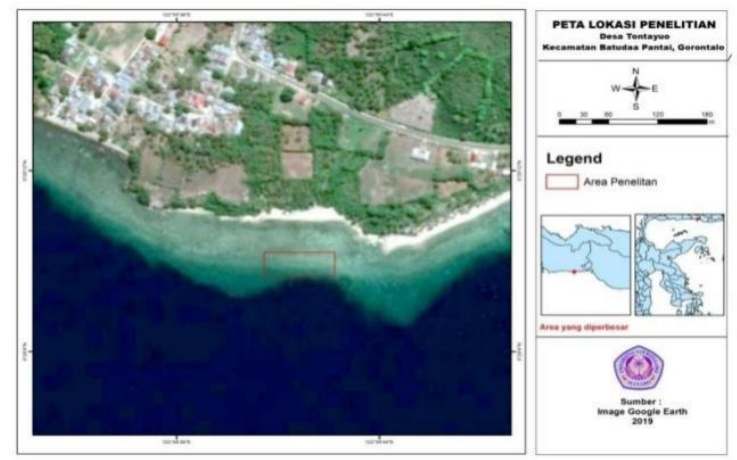

Gambar 1. Peta lokasi penelitian.

Keterangan: Tanda kotak warna merah adalah lokasi pengambilan sampel karang (Image Google Earth, 2009).

\section{Alat dan Bahan}

Material yang digunakan adalah alat snorkeling, pahat, palu, toples, microskop Olympus CX41, penghubung mikroskop dan komputer Olympus DP21, Komputer ST24 monitor, aplikasi optica view 7 (software), laptop, gelas ukur, pipet, pinset, pensil karet, mistar, slide glass, cover glass, asam asetat 
$40 \%$, formalin $40 \%$, alkohol $70 \%$, bayclin, imerssion oil, karang uji Pocillopora sp.

\section{Teknik Pengumpulan Data Pengambilan sampel karang uji}

Sampel karang uji, Pocillopora sp. diambil di area ekosistem terumbu karang pantai Tontayuo pada kedalaman kira-kira 25 meter pada saat air surut terendah dengan menggunakan alat snorkeling. Karang uji diambil 4 (empat) koloni, kemudian itu

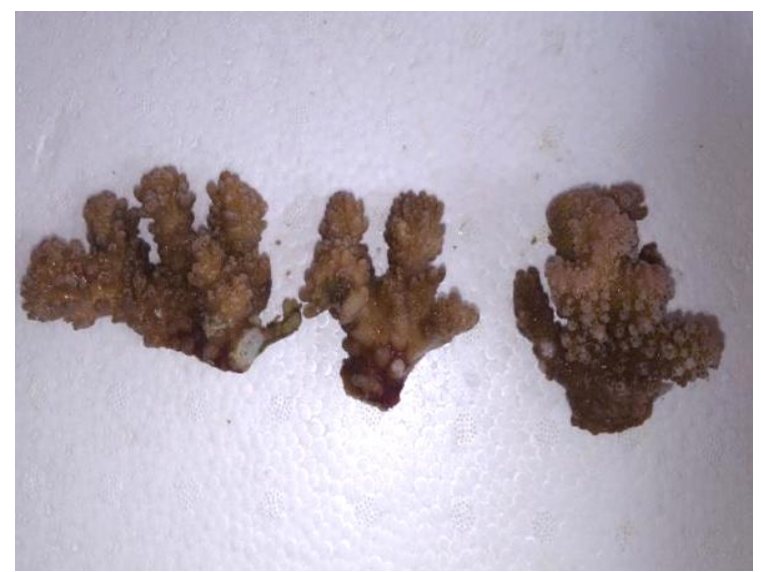

A

Gambar 2. Koloni karang uji, Pocillopora sp.

Keterangan: A. Koloni karang dalam keadaan hidup, B. Skeleton karang.

\section{Dekalsifikasi karang uji}

Tiga koloni karang yang telah diawetkan didekalsifikasi selama tiga hari dengan menggunakan larutan kimia, yaitu campuran formalin $40 \%$ dan asam asetat 40 $\%$ dengan perbandingan 1:1 untuk mendapatkan jaringan lunak yang akan digunakan untuk uji nematosit dengan mengacu pada metode Paruntu, dkk. (2000).

\section{Uji tipe nematosit di bawah mikroskop} Jaringan karang lunak hasil dekalsifikasi diuji di bawah mikroskop (Olympus CX41) dengan lensa objektif pembesaran x100 (immersion oil) yang terhubung dengan monitor komputer untuk diletakkan dalam wadah ember berisi air laut, dan dibawa ke daratan. Setelah di darat, koloni karang uji diambil foto untuk keperluan dokumentasi (Gambar 2). 3 (tiga) koloni karang uji diawetkan dalam wadah toples yang berisi alkohol $70 \%$, sedangkan 1 (satu) koloni karang lainnya diputihkan dengan larutan pemutih (bayclin) selama 3 (tiga) hari untuk memperoleh skeleton yang bersih. Sampel karang uji yang telah diambil, selanjutnya disimpan di Laboratorium Biologi Laut FPIK UNSRAT.

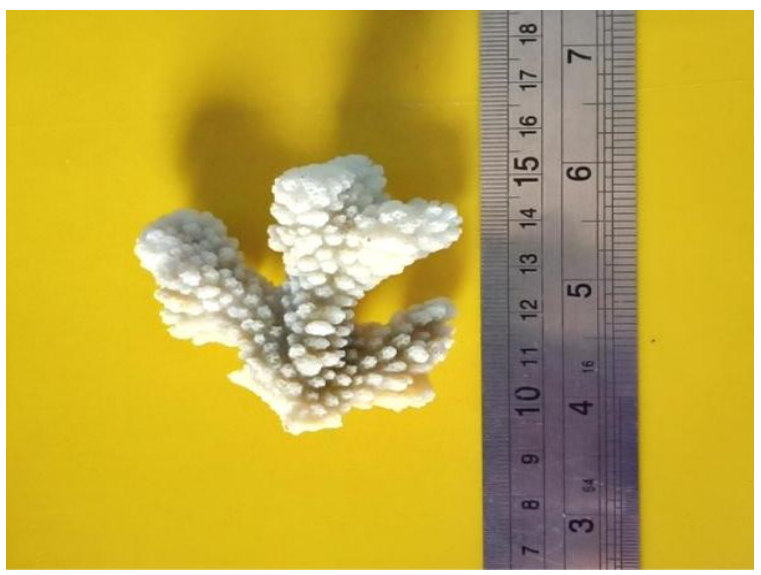

B menguji tipe, komposisi, dan dimensi nematosit. Jaringan karang lunak diambil potongan kecil dengan pinset, kemudian ditempatkan dan dibilas dalam cawan petridis berisi air tawar. Dari potongan kecil tersebut diambil bagian terkecil lagi dengan pipet, kemudian diletakkan pada slide glass, di bawah cover glass, dipencet dengan bantuan pensil berkaret sampai lebur dan terlihat tipe nematosit secara jelas di bawah mikroskop. Pengujian tipe-tipe nematosit di bawah mikroskop mengacu pada metode Paruntu (1996).

\section{Pengukuran dimensi nematosit}

Dimensi nematosit diamati di bawah mikroskop Olympus CX41 dengan 
pembesaran lensa objektif x100 yang terhubung dengan Komputer ST24 monitor, dan diukur dengan menggunakan aplikasi optica view 7. Lebar dan panjang kapsul nematosit diukur dari sisi ujung yang satu ke sisi ujung lainnya pada bagian luarnya, sedangkan panjang tangkai diukur dari ujung tangkai yang satu sampai ujung tangkai bentuk huruf "V" (Gambar 3). Pengukuran dimensi nematosit karang uji mengacu pada metode Paruntu (1996).

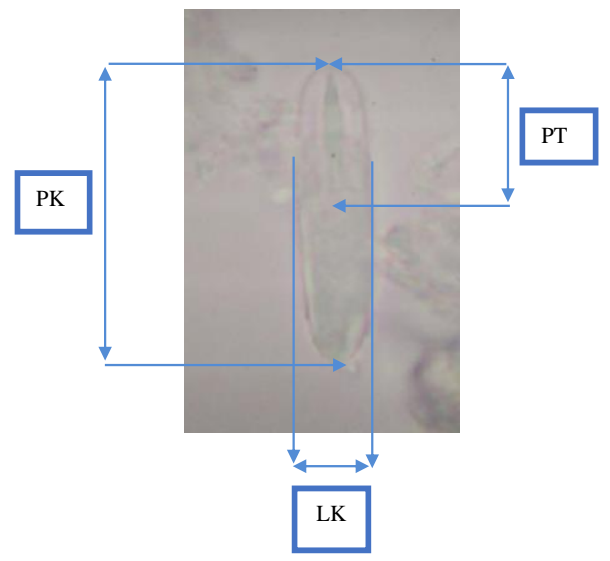

Gambar 3. Cara mengukur dimensi nematosit MpM.

Keterangan: $\mathrm{PK}=$ panjang kapsul nematosit; LK = lebar kapsul nematosit; PT = panjang tangkai nematosit.

\section{Komposisi tipe nematosit}

Tipe-tipe nematosit utama saja yang digunakan pada perhitungan komposisi nematosit, sedangkan tipe-tipe nematosit yang sulit dihitung dan diidentifikasi dapat diabaikan. Setiap tipe nematosit dari koloni karang dari setiap jenis dihitung paling minimal 10 sel nematosit yang berada dalam 15 area yang ditetapkan dan tertampil di monitor komputer.

\section{Analisis Data}

Data dimensi nematosit (dalam satuan mikrometer) dianalisis di komputer menggunakan optica view 7 (software). Rata-rata dimensi dan standar deviasi dari setiap tipe nematosit dihitung menggunakan microsoft excel 2007.

\section{HASIL DAN PEMBAHASAN}

Pocillopora sp. memperlihatkan tipe dan komposisi nematosit utama, yaitu mikrobasic $p$-mastigophora (MpM) sebesar $91,49 \%$ dan holotrichous isorhizas (HI) sebesar 8,51 \%. Paruntu, dkk. (2000) melaporkan bahwa $P$. damicornis, koloni dewasa memiliki tipe dan komposisi nematosit utama, yaitu MpM-I sekitar $10 \%$, MpM-II $5 \%$, HI kecil $3 \%$, dan MbM $45 \%$, spirosit $37 \%$. Paruntu, dkk. (2013) melaporkan bahwa pada jenis karang $P$. eydouxi memiliki tipe dan komposisi nematosit utama, yaitu MpM sebesar $50 \%$ dan $\mathrm{HI} 50 \%$, P. woodjonesi memiliki MpM 55 $\%$ dan $\mathrm{HI} 45 \%$, dan $P$. verrucosa memiliki MpM $100 \%$. Gagu, dkk. (2019) melaporkan bahwa pada $A$. florida mempunyai tipe dan komposisi nematosit utama, yaitu $\mathrm{HI}$ sebesar $4,44 \%$ dan MpM 95,56 \%, A. divaricata memiliki MpM $100 \%$. Perbedaan tipe dan komposisi nematosit karang, baik pada penelitian sekarang ini maupun penelitian sebelumnya diduga karena perbedaan jenis karang yang diteliti. Tipe HI merupakan tipe nematosit yang sangat jarang ditemukan dalam jaringan tubuh karang yang dilaporkan di atas, sedangkan tipe MpM merupakan tipe yang paling dominan dan spesifik untuk genus Pocillopora dan Acropora.

MpM berbentuk seperti kapsul yang mempunyai tangkai dan benang berduri dan beracun, serta ujung tangkai bentuk huruf "V". HI berbentuk seperti kapsul yang hanya memiliki benang yang berduri dan beracun, dan tidak mempunyai tangkai. Tipe dan komposisi nematosit $\mathrm{MpM}$ dan $\mathrm{HI}$ dapat dilihat pada Gambar 4 dan Gambar 5. 

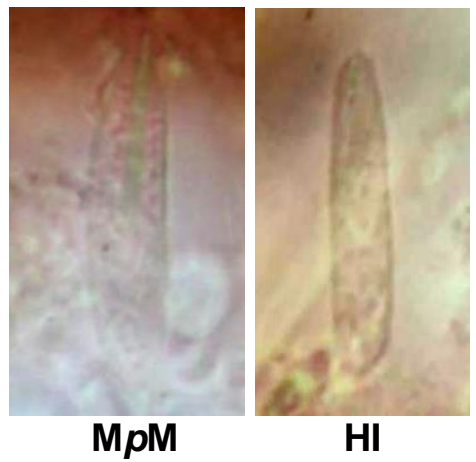

Gambar 4. Tipe nematosit MpM dan HI pada Pocillopora sp.

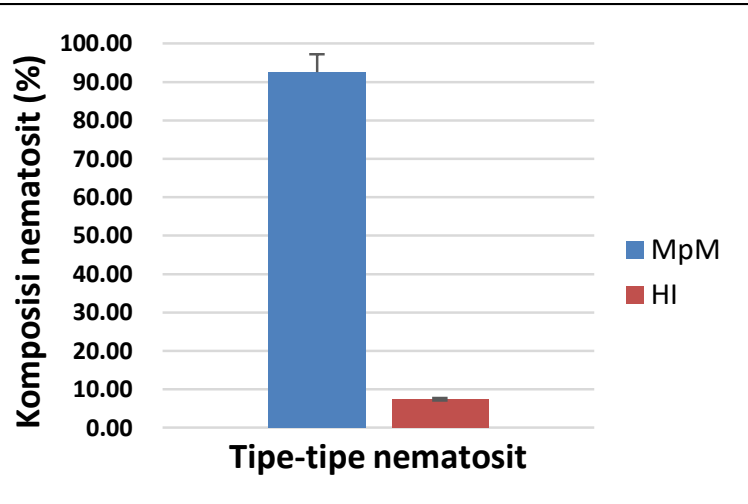

Gambar 5. Komposisi nematosit Pocillopora sp.

Penelitian saat ini memberikan informasi bahwa Pocillopora sp. memiliki rata-rata panjang kapsul MpM sebesar 261,34 $\mu \mathrm{m}$, lebar kapsul 60,36 $\mu \mathrm{m}$ dan panjang tangkai 121,13 $\mu \mathrm{m}$ (39 sel nematosit yang diukur untuk setiap dimensi nematosit), sedangkan $\mathrm{HI}$ memiliki rata-rata panjang kapsul 200,2 $\mu \mathrm{m}$ dan lebar kapsulnya 44,69 $\mu \mathrm{m}$ (4 sel nematosit yang diukur untuk setiap dimensi nematosit).

Mariscal (1974) menyatakan bahwa MpM pada umumnya digunakan oleh karang untuk menangkap makanan dengan menusuk ke objek mangsa dan juga berfungsi sebagai pertahanan tubuhnya. Tipe nematosit $\mathrm{HI}$ digunakan fauna Cnidaria untuk menyerang predator hingga menyebabkan nekrosis pada jaringan tubuhnya (Den Hartog, 1977). Tipe MpM dan HI yang ditemukan pada Pocillopora sp. dalam penelitian sekarang ini dapat juga diduga berfungsi seperti yang dijelaskan oleh Mariscal (1974) dan Den Hartog (1977).

\section{KESIMPULAN DAN SARAN}

\section{Kesimpulan}

Penelitian sekarang ini memperlihatkan bahwa:

1. Paling sedikit dua tipe nematosit yang didapatkan pada Pocillopora sp., yaitu MpM dan HI.

2. Komposisi tipe nematosit pada karang Pocillopora sp. menunjukkan bahwa tipe nematosit dominan yaitu MpM sebesar $91,49 \%$, sedangkan $\mathrm{HI}$ hanya sebesar $8,51 \%$.

\section{Saran}

Penelitian ke depan disarankan untuk mengidentifikasi karang ini pada tingkatan spesies dan mempelajari lebih mendalam berbagai spesies karang dalam genus Pocillopora berdasarkan tipe dan morfologi nematosit yang berguna dalam taksonomi karang Scleractinia.

\section{DAFTAR PUSTAKA}

Fautin, D.G. 2009. Structural diversity, systematics, and evolution of cnidae. Toxicom 54: 1054-1064. 11 hal.

Gagu, S., S. Darwisito, B.Th. Wagey, A.P. Rumengan, A.B. Rondonuwu, dan C.P. Paruntu. 2019. Dimensi dan komposisi nematosit pada karang scleractinia, Acropora florida dan Acropora divaricata di Pantai Motandoi Selatan Kabupaten Bolaang Mongondow Selatan. Jurnal Pesisir dan Laut Tropis. Volume 7 Nomor 3. Hal. 227233. 
Hartog J.C. Den. 1977. The marginal tentacles of Rhodactis sanctithomae (corallimopharia) and the sweeper tentacles of Montrastrea cevemosa (Scleractinia) their cnidom and possible function. Proc. 3rd Int. Coral Reef Symp. 1: 463-469.

Hidaka, M. and K. Yamazato. 1985. Color morphs of Galaxea fascicularis found in the Reef Around the Sesoko Marine Science Center. Galaxea, 4: 33-35.

Image Google Earth. 2009.

Lang, J.C. 1986. Whatever works: The variable importance of skeletal and non-skeletal character in scleractinian taxonomy. Palaeontogr. Amer., 54: 18-44.

Mariscal, R.N. 1974. Nematocyst. In Muscatine, L. and H. M. Lenhoff (eds). Coelenterates biology: reviews and new perspective. Academy Press. New York. Hal.129-178.

Paruntu, C.P., 1996. Studies on cnidae of scleractinian corals: Development changes in cnida composition and spatial distribution of cnidae along mesenterial filaments. Master Thesis. University of Ryukyus Okinawa Japan. P. 1-58.

Paruntu, C.P. 1997. Spatial distribution of cnidae along mesenterial filaments of Pachyseris rugosa. Berita Fakultas Perikanan. UNSRAT. 5 (1-2).

Paruntu, C.P., K. Hidaka, and M. Hidaka. 2000. Developmental changes in cnidae composition of the coral
Pocillopora damicornis. Galaxea, JCRS. Japan. 2 : 23-28.

Paruntu, C.P., H. Rifai, dan J.D. Kusen. 2013. Nematosit dari tiga spesies karang scleractinia, genus Pocillopora (Nematocysts of the three scleractinian corals of genus Pocillopora). Jurnal Perikanan dan Kelautan Tropis. Vol. IX, No. 2. Hal .60-64.

Paruntu, C.P. 2014. Nematosit dan tiga macam warna karang Galaxea fascicularis (Linnaeus) ditemukan di terumbu karang pantai Malalayang Kota Manado. Jurnal Pesisir dan Laut Tropis. Hal. 19-23.

Paruntu, C.P. dan N. Souw. 2014. Morfologi nematosit dari dua karang scleractinia, Seriatopora hystrix dan Seriatopora caliendrum. Jurnal LPPM Bidang Sains dan Teknologi, Vol. 1, No. 1. Hal. 113- 120.

Paruntu, C.P. and S. Darwisito. 2016. Nematocysts of the mesenterial filaments of Pachyseris rugosa. The International Conference on Marine Biodiversity. Hal.12-15.

Pires, D.O. dan F.B. Pitombo. 1992. Cnidae of the Brazillian Mussidae (Cnidaria: Scleractinia) and their value in taxonomy. Bull. of Mar. Sci. 51: (2) 231244.

Watson, G.M. and R.L. Wood. 1988. Colloqioum on terminology. Hal. 2123 In: Hessinger, D.A, and H.M, Lenhoff (eds). The Biology of Nematocyst, Academic Press Inc, San Diego. 